\title{
El Conflicto Del Cenepa: Su Camino Hacia La Paz
}

The Conflict Of Cenepa: His Path To Peace

\section{Cristian Daniel Valdivieso 0jeda ${ }^{1}$}

\section{RESUMEN}

El presente texto examina el proceso de transformación de paz del conflicto Ecuador-Perú 1995 mediante el lente de los Estudios de Seguridad Internacional tomando conceptos como conflicto armado, negociación y peacekeeping. Se concluye definiendo al conflicto como "conflicto armado de intensidad menor" resuelto por negociación y mediación. Además la misión de observadores MOMEP fue decisiva en la consolidación de paz.

Palabras clave: Conflicto; Cenepa; peacekeeping.

\begin{abstract}
This paper examines the transformation of peace process Cenepa conflict Ecuador-Perú 1995 through the lens of International Security Studies taking concepts such as armed conflict and negotiation. It is concluded by characterizing the conflict as a "lower intensity conflict" in a context of "old wars". In addition, the MOMEP observer mission was decisive in peace consolidation.
\end{abstract}

Keywords: Conflict; Cenepa; peacekeeping.

\section{INTRODUCCION}

Los Estados latinoamericanos han vivido problemas limítrofes desde tiempos pasados mostrando estragos hasta las últimas décadas. Según Domínguez (1984, p. 1) la amenaza de guerra entre Chile y Argentina en 1978 por el Canal de Beagle, y la disputa por el acceso de Bolivia al Pacífico en 1970 son prototipo de esta continuidad de conflictos.

Siendo así, el presente trabajo tiene como finalidad dar un panorama del proceso de paz en el conflicto del Cenepa de 1995 entre Ecuador y Perú. De tal modo, dos

\footnotetext{
1 Estudiante de Relaciones Internacionales e Integración de la Universidad Federal de Integración Latinoamericana (UNILA), Foz do Iguaçu, Brasil.

Conjuntura Global, Vol. 4, n. 2, maio/ago., 2015, p. 221-235.
} 
cuestiones son problematizadas. La primera es una categorización del conflicto entre los conceptos de "conflicto armado" y "guerra" según la concepción desarrollada por el The Uppsala Conflict Data Program (UCDP). Conjuntamente, se establece una conexión con el abordaje propuesto por Mary Kaldor (2006) referente a "viejas guerras" y "nuevas guerras". Este complemento es importante para entender que el conflicto del Cenepa tiene la característica de ser un conflicto inter-estatal a pesar de encontrarse en un ambiente de auge de conflictos intra-estatales. La segunda cuestión busca establecer una identificación de la Misión de Observadores Militares Ecuador-Perú (MOMEP) como un instrumento de peacekeeping tradicional caracterizado por las Naciones Unidas (2008) como recurso de manutención de paz.

Por último el trabajo está estructurado en tres ejes. Primeramente se exponen los conceptos y definiciones que serán aplicados al caso de estudio del conflicto del Cenepa. En segundo lugar, se muestra un apañado histórico de las diversas disputas territoriales entre Ecuador y Perú, que permite marcar el camino hacia el conflicto de 1995. Finalmente, se da un enfoque concreto a la transformación del conflicto rescatando y aplicando al caso del Cenepa las definiciones y conceptos desarrollados anteriormente.

\section{CAMINOS DE PAZ}

El siglo XX ha sido sellado por eventos catastróficos para la humanidad. Ricardo Seitenfus (2005) explora los escalones de este siglo mostrando dos grandes guerras, genocidios y avances tecnológicos que darían al hombre por primera vez en la historia la capacidad de autodestruirse. Siendo así, la década de 1940 marca el fin de uno de los sucesos más relevantes, la Segunda Guerra Mundial.

Este guerra "fue una experiencia casi universal" (JUDT, 2008, p. 28) y no apenas en su alcance geográfico sino también por sus consecuencias. Según nuestra concepción su universalismo figuró en tres ejes -económico, bélico y de seguridad. El primero, porque su desenlace permeó el inicio de un nuevo orden monetario internacional basado en el Acuerdo Bretton Woods en 1944 que establecería el control norteamericano sobre la economía global. Segundo, referente a su alcance a las Américas, fue marcado por "el ataque a Pearl Harbor, en diciembre de 1941, [...] se transforma realmente en una guerra mundial" (SEITENFUS, 2005, p. 173) que llevó a Brasil a enviar cerca de 26 mil soldados a luchar en Europa. En tercer lugar, por la 
necesidad de crear un mecanismo que mantenga la seguridad de los Estados. Así, en 1945 se crea la Organización de las Naciones Unidas (ONU) como nueva estructura cuya finalidad, en su artículo 1 es "Mantener la paz y seguridad internacionales" (CARTA DE LAS NACIONES UNIDAS, 1945).

Ya en el pos-guerra durante la dicotomía producida por la Guerra Fría dirigida por dos polos de poder -Estados Unidos y la Unión Soviética- brotan the peace studies como menciona Johan Galtung (1985, p. 1). Básicamente la disciplina da una primera mirada a la paz en el sentido que Galtung (1969, p. 172) determina como mera ausencia de violencia, paz negativa. Aun así, estos estudios influyen en el Sistema Internacional creando instrumentos de consolidación de paz que mediante las Naciones Unidas se aplican en conflictos inter-estatales.

La Organización de Supervisión de Tregua de las Naciones Unidas (establecida en 1948) fue montada para monitorear ceses de fuego, supervisar acuerdos armisticios, prevenir un escalamiento de incidentes y asistir otras operaciones de manutención de paz en la región de Medio Oriente (NEWMAN, RICHMOND; PARIS, 2010, p. 6).

La década de 1980, capta una amplia gama de fuentes conceptuales inspiradas en la emergencia de nuevos asuntos globales, como los desafíos en cuestiones ambientales. Posteriormente, para la década de 1990 aparecen nuevos conflictos de cuño intraestatal. A consecuencia de esto Mary Kaldor sustrae la acción interna de los individuos como referentes dentro de un conflicto y coloca una distinción entre "viejas guerras" y "nuevas guerras". Las primeras, son "libradas entre Estados, mediante Fuerzas Armadas uniformadas, donde la batalla era el choque decisivo" (KALDOR, 2006, p. 12). Ejemplo de este tipo de conflicto son la I y II Guerras Mundiales en la cual se enfrentaron los ejércitos de los Estados involucrados. Por su parte, las "nuevas guerras" son aquellas "libradas por redes de actores estatales, y no estatales, a menudo sin uniformes [...] al modo de milicias" (KALDOR, 2006, p. 13). En otras palabras, son conflictos librados en un contexto de Estado en desintegración, incentivados por inconformidad interna. Son guerras donde la mayor parte de la violencia va dirigida a la población civil conforme la acción de grupos insurgentes e incluso limpieza étnica permeando un sentimiento de miedo y odio en la población afectada.

Existe un vacío entre definiciones de guerra y conflicto armado, por tanto es preciso comprender lo que es conflicto armado y sus respectivas dimensiones. Para tal 
efecto, el Departament of Peace and Conflict Research de la Universidad de Uppsala, creado en el año de 1970, ayuda a definir "conflicto armado" como una incompatibilidad entre dos partes que al enfrentarse mediante el uso de la fuerza armada deja un resultado de por lo menos 25 muertes en combate en el periodo de un año. De conflicto armado se ramifican dos distinciones; la primera es el "conflicto de menor intensidad" que es cuando existen por lo menos 25 muertes y no sobrepasa de mil por un año. La segunda distinción hace referencia a la "guerra", engendrada cuando el número de víctimas en un año sobrepasa las 1000. Como ilustración de este tipo de conflicto se observa lo ocurrido en Uganda en 1981 hasta 1989, el cual es caracterizado como una "guerra" al mantener un promedio de muertes anual de 1224 durante esos nueve años. Conviene distinguir también que, a partir de 1990 hasta 1995 se transforma en un "conflicto de menor intensidad" con un promedio anual de 398 muertes. Esto demuestra que un conflicto puede oscilar entre "guerra" y "conflicto de menor intensidad".

A este nivel de comprensión de este fenómeno, es importante resaltar que los conflictos armados pueden ser prevenidos de escalar en una guerra. Para ello existen diversos instrumentos como los son la negociación y la mediación. Según Bercovitch y Jackson (2001, p. 60) la negociación es "un proceso en que Estados o actores se comunican o intercambian propuestas en un intento de terminar un conflicto y establecer sus relaciones futuras [traducción nuestra]". Por otro lado, mediación tiene una mayor acogida por abarcar conflictos extensos, o por ser una alternativa cuando la negociación no es viable. Es una,

\footnotetext{
Extensión de negociaciones donde las partes buscan la asistencia, o aceptan una oferta de ayuda, de una parte no involucrada directamente en el conflicto para resolver sus diferencias sin involucrar la autoridad de la ley [traducción nuestra]. (Id. p. 60).
}

Existe un gran debate entre cuál de estos dos instrumentos es más efectivo, sin embargo se debe tomar en cuenta que son diversos los factores que demandan su respectiva utilidad: la naturaleza de la disputa, las características de los participantes, la coyuntura global dentro de la cual se encuentran y sobre todo el resultado que puede traer dicho instrumento, para todos los participantes.

La Organización de las Naciones Unidas cuyo fin es "Mantener la paz y seguridad internacionales" (CARTA DE LAS NACIONES UNIDAS, 1945), se ha constituido como uno de los grandes agentes mediadores de conflictos mediante sus instrumentos de paz: 
peacemaking, peacebuilding, preventive diplomacy y el peacekeeping. Es determinante establecer según las Naciones Unidas (2008) que el peacekeeping es una técnica para mantener la paz implementando acuerdos alcanzados por los mediadores. Este instrumento ha sido invocado de manera muy frecuente y como ejemplo de esto tenemos la acción de la UNEF I en Egipto (1956-1967) que fue una respuesta a la crisis de Suez. Sin embargo, no se puede dejar de lado que "Durante años, la manutención de paz se ha involucrado desde un modelo militar primario de observación de cese al fuego y separación de fuerzas luego de guerras inter-estatales" (NACIONES UNIDAS, 2008, p. 18) esto demuestra que no ha existido modificación relevante en cuanto al modo tradicional de consolidación de paz. Conforme Boutros-Ghali (1992) el peacekeeping tradicional comprenderá un despliegue más militar y policial con el fin de prevenir los conflictos y tomar la paz.

Tras el establecimiento de estos criterios conceptuales, el próximo apartado desarrollará un histórico específicamente sobre el conflicto del Cenepa. El mismo buscará determinar las raíces en las cuales se fundamenta dicha divergencia entre Ecuador-Perú.

\section{UNA HISTORIA DE CONFLICTOS}

El conflicto del Cenepa debe ser comprendido como el producto de una serie de eventos históricos que han marcado las relaciones entre Ecuador y Perú. Siendo de este modo necesario retroceder en el tiempo hasta el año de 1822 cuando Ecuador pasa a formar parte de la Gran Colombia, iniciativa generada por Simón Bolívar e instituida en la unión de Venezuela y Nueva Granada. Sin embargo, tras la independencia peruana en 1824 se da un intento de anexar regiones de la Gran Colombia a la nueva república independiente. Esto culminará en la Batalla de Tarqui en el año de 1829. Este evento llevará a la firma del Tratado de Guayaquil y, en 1830, del Protocolo PedemonteMosquera "donde se limitaba la frontera del Ecuador hacia la izquierda del Río Marañon o Amazonas" (BURNEO, 2010, p. 3). De este modo, es visible que la formación de los Estados da inicio a la preocupación por las fronteras y límites territoriales, y a su vez trae consigo la resonancia de un conflicto que será sentido a largo plazo.

El año de 1830 muestra una Gran Colombia desestructurada y un Ecuador independiente cuyo artículo 6 de la carta magna dice "El territorio del Estado 
comprende los tres departamentos del Ecuador en los límites del antiguo Reino de Quito" (CONSTITUCIÓN DEL ECUADOR, 1830). Esto demostraba que Ecuador se extendía hasta los límites con el río Amazonas; sin embargo, el fin de la Gran Colombia generó invalidez en el Tratado de Guayaquil que sustentaba al Protocolo PedemonteMosquera creando así un problema limítrofe con relación a la soberanía sobre el río Amazonas.

A partir del año 1830 surgen múltiples divergencias e intentos de negociación, como lo fue el Protocolo de Oyanguren-Ponce de 1924 donde se comprometían ambos Estados a someterse al arbitraje del Presidente de los Estados Unidos. Finalmente, en el año de 1941 se produce una invasión por parte de Perú y tras la mediación de cuatro países, que fueron denominados los garantes de la paz - Argentina, Brasil, Chile, y Estados Unidos-, se acordó la suscripción del Protocolo de Paz, Amistad y Límites de Río de Janeiro en el año de 1942. Sin embargo, este Protocolo fue considerado nulo por Ecuador por tres motivos. Primero por encontrarse Ecuador sometido e invadido por Perú al momento de firmar el tratado; segundo porque el protocolo reconoce en su artículo segundo la ocupación peruana de territorios ecuatorianos "El Gobierno del Perú retirará dentro del plazo de 15 días, a contar desde esa fecha, sus fuerzas militares a la línea que se halla descrita en el art. VIII de este protocolo" (PROTOCOLO DE PAZ, AMISTAD Y LÍMITES ENTRE EL ECUADOR Y PERÚ, 1942). Finalmente, por no cumplirse el señalado divisor de aguas entre los ríos Zamora y Santiago debido a la existencia de un tercer río denominado Cenepa. En torno de este tercer problema es que se extiende hasta el año de 1995 una gran incertidumbre en torno a la delimitación de esta frontera (Figura 1).

Desafortunadamente Ecuador había firmado el Protocolo de Río de Janeiro de 1941 lo cual representaba una pérdida de $13.000 \mathrm{~km} 2$ de tierras" (BATISTA, 2005, p. 128) de tal modo que cualquier provocación sería un desencadenante letal para un conflicto, pues era un foco de enfrentamiento entre ambos Estados. Anexado a esto, el próximo apartado tratará específicamente sobre el conflicto y su proceso de transformación hacia la paz mediante la aplicación de los conceptos abordados en la primera sección del trabajo. 


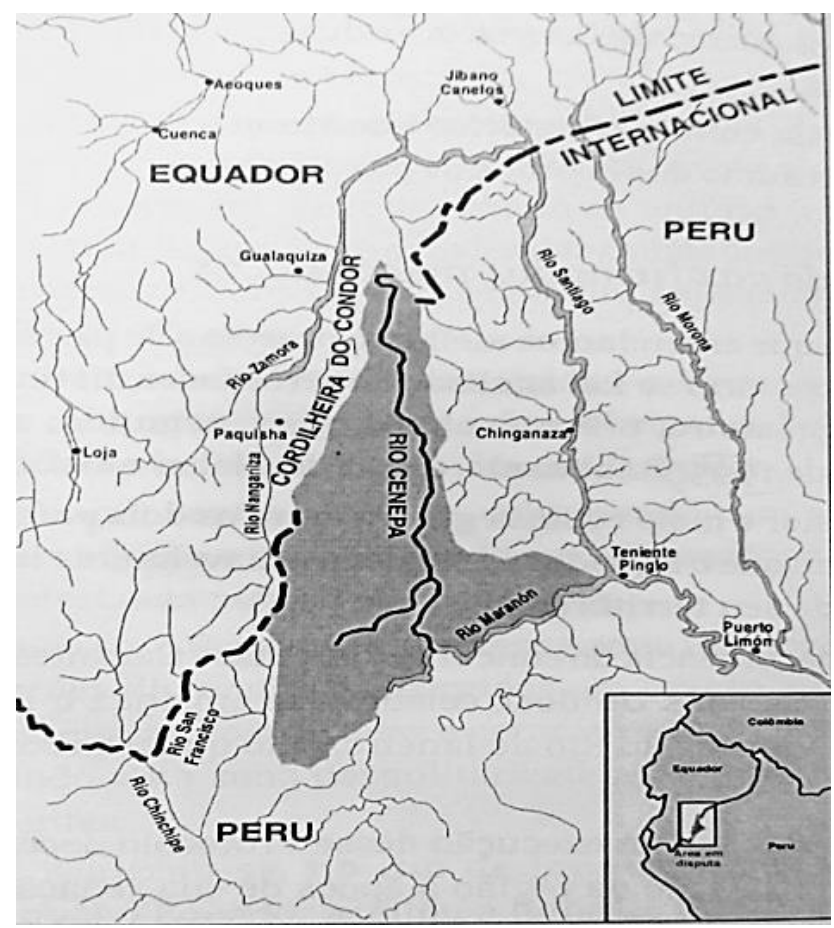

Figura 1. Área de disputa fronteriza Ecuador- Perú. CRUZ, Sergio, 2005, p. 130.

\title{
CONFLICTOS, INSTRUMENTOS Y CONCEPTOS EN EL CENEPA
}

\begin{abstract}
El ruido producido por el ataque, hizo estremecer al Valle del Cenepa. [...]El Tcrn. Luis Aguas, tomó personalmente la radio y arengó a las tropas ecuatorianas. Desafió a todos los soldados a tomar sus armas y defender con el último suspiro cada milímetro de nuestro territorio, haciendo estremecer de emoción a todos los presentes en la zona. (TELLO, 2011)
\end{abstract}

El conflicto del Cenepa tuvo una representación dual para Ecuador y Perú. Por un lado, el conflicto bélico se hacía presente desde el día jueves 26 de enero de 1995 cuando tropas ecuatorianas son ordenadas de desalojar un helipuerto peruano infiltrado en Base Norte, territorio ecuatoriano. Según Tello (2011, p. 42) el ataque a Base Norte dio génesis a las hostilidades entre los ejércitos de ambos Estados. Por otro lado, la parte diplomática se ponía en acción a partir de la noche del 30 de enero de 1995 cuando el Dr. Marcelo Fernández de Córdoba fue delegado por el presidente Sixto Durán Ballén para presidir a la delegación ecuatoriana que hará parte de las conversaciones con el fin de alcanzar un acuerdo.

En cuanto al conflicto armado suscitado en el territorio del Alto Cenepa, cabe destacar que este impase es un conflicto armado de intensidad menor como define la 
enciclopedia UCDP (1970). Pues su alcance, según Espinosa (1999, p. 115) fue de cerca de 500 individuos que perdieron la vida de parte de ambos Estados a lo largo del enfrentamiento. Sin embargo, bajo la fuente de datos del Ejército Ecuatoriano (2011, p. 301) en los caídos por parte del Estado ecuatoriano constan 32 combatientes. Los mismos que son conocidos como los "Héroes del Cenepa"; esto permite concluir que el resto de combatientes caídos fueron de parte del Estado peruano.

Prosiguiendo con el análisis, este conflicto de menor intensidad puede ser complementado con la categorización que hace Mary Kaldor (2006) sobre las viejas guerras. Pues, tras establecer, de nuestra parte, la distinción de que la guerra es un tipo de conflicto, se puede decir que Ecuador y Perú tuvieron un encuentro al puro estilo de las viejas guerras. Esta categorización es reafirmada tras identificar dentro del conflicto del Cenepa ciertos valores como: el enfrentamiento de tropas estatales uniformadas, el choque físico de fuerzas armadas, además que tenía la finalidad de consolidar el Estado. Quizá sea atrevido referirse a carencia de consolidación del Estado-nación, sin embargo los Estados ecuatoriano y peruano, al no tener definido su territorio deja incongruente la definición de Estado como un ente con personalidad jurídica con pueblo, territorio, gobierno y finalidad (REMIRO, 2007, p. 98).

El combate armado del día 26 de enero, cuando Ecuador desalojó de su territorio a las tropas peruanas, desencadenó una ofensiva peruana directa al día siguiente. Este ataque iba dirigido a dos destacamentos, Teniente Hugo Ortiz (Figura 2) y Etza, los cuales "según su diplomacia, se ubicaban en territorio peruano" (MONCAYO, 2011, p. 47). Sin embargo, las tropas peruanas no se encontraban en la capacidad de sostener dos ofensivas por lo cual orientaron sus esfuerzos a la región de Tiwintza. A pesar de realizar tal movimiento, la defensiva ecuatoriana fue mayor incluso en los días 7 y 8 de febrero cuando la milicia peruana ejerció mayor presión con el fin de conquistar Tiwintza. 


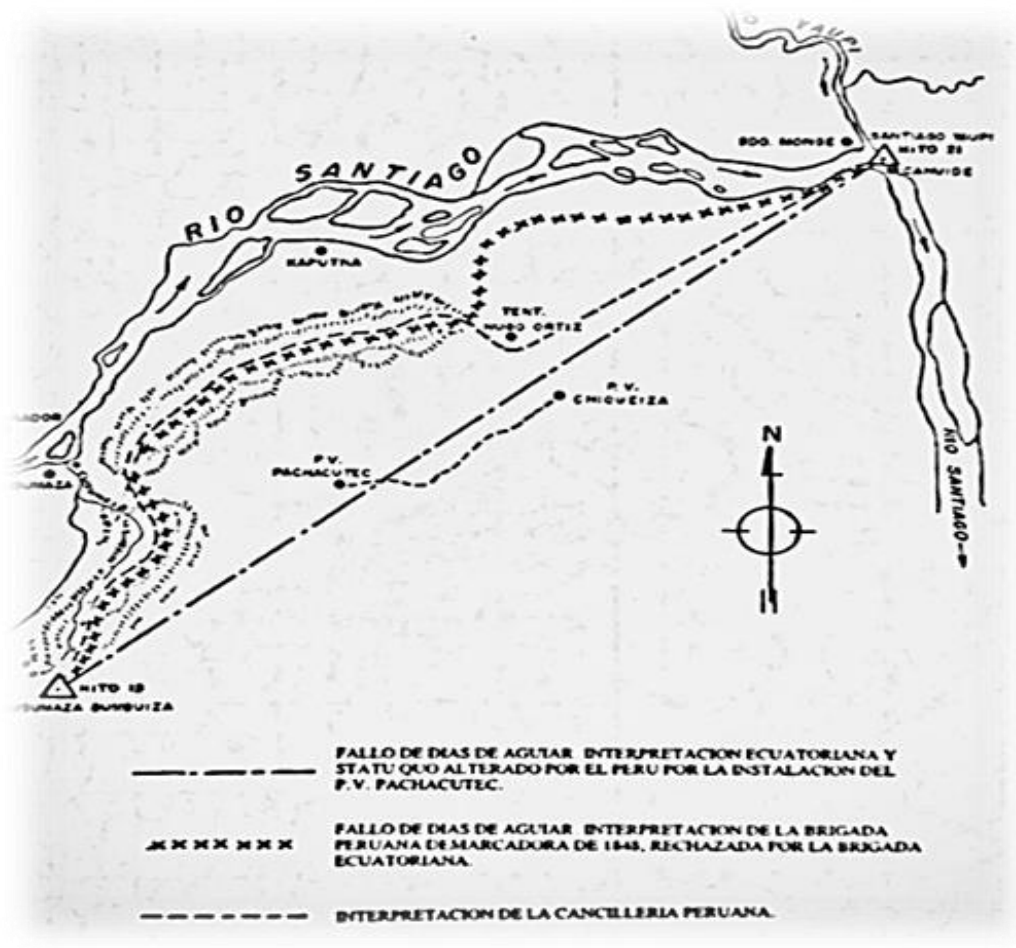

Figura 2. Interpretaciones ecuatoriana y peruana con respecto al Fallo de Dias de Aguiar.

Este triunfo generó efectos positivos y negativos en el devenir del conflicto. Cesaron los bombardeos impunes a las posiciones ecuatorianas, lo cual alivió las tensiones que vivían los combatientes. Parecería ser que también influyó en la decisión de las autoridades peruanas de aceptar el cese de fuego ante la inutilidad de sus esfuerzos para capturar los objetivos. (MONCAYO, 2011, p. 53)

Es imprescindible destacar que alrededor de las batallas que se dieron entre el 26 de enero y el 27 de febrero, existió una fuerte presión mediática por parte del Perú. Fujimori era candidato a la reelección presidencial por lo cual su motivación para exaltar su personalidad de líder se veía enfocada en la toma de Tiwintza y por su vez derrotar a Ecuador en este conflicto. Siendo así, el día 9 de febrero,

El Perú realizó en la tarde, un bombardeo masivo sobre las posiciones ecuatorianas de Tiwintza, en las cabeceras del río Cenepa... de modo que nuestras tropas han quedado listas para el asalto final. Un día después tuvo que informar a su país que [...] dos aviones Sukhoi, un avión A-37 y un helicóptero fueron derribados, el viernes 10 de febrero, por la aviación y artillería ecuatorianas. (MONCAYO, 2011, p. 53

Tras observar múltiples intentos fallidos por establecer una separación entre las fuerzas militares, la diplomacia de ambos países entra en acción y especialmente bajo el apoyo de los países garantes del Protocolo de Rio de Janeiro de 1942. De este modo el 
día 17 de febrero se realiza la firma de la Declaración de Paz de Itamaraty. En este avance en cuanto a los diálogos entre las partes, merece oportuno destaque el instrumento aplicado para la resolución que en este caso es una negociación, como punto inicial, de los delegados de ambos países. El representante de Ecuador, Dr. Marcelo Fernández de Córdoba, menciona que "las dificultades de la negociación surgieron en cada momento, no solo por las argucias, falsedades y trucos del negociador peruano [...] sino también por los obstáculos propios de nuestra parte" (FERNÁNDEZ, 2011, p. 291).

Aun así, el autor menciona que la Declaración de Paz fue un verdadero tratado que posee grandes alcances, como: el reconocimiento peruano de la existencia de un problema fronterizo, la no santificación del Protocolo de Rio de Janeiro como única solución, la fiel garantía de una paz consolidada y finalmente la apertura a la negociación de impases encontrados entre ambos Estados. Un punto importante de esta Declaración es que permitió formalizar el cese de fuego por parte de ambos países, siendo que el día 28 de febrero se firma la Declaración de Montevideo como un agradecimiento a la participación de los países garantes. A su vez, los garantes se comprometen a verificar el respectivo cese de fuego por lo que se crea una Misión de Observadores Militares Ecuador-Perú (MOMEP).

La MOMEP fue un instrumento valioso dentro del conflicto. Erigido el día 14 de marzo de 1995 y bajo adecuada ligación a la Declaración de Paz del Itamaraty. Este recurso puede ser entendido como una misión de peacekeeping tradicional por el hecho de que "supervisó el cesar fuego, separó y desmovilizó las fuerzas en confronto y creó un área desmilitarizada" (BATISTA, 2005, p. 132). Sin embargo, su importancia radica en la misma necesidad de un cuerpo imparcial que permita el fiel seguimiento de lo estipulado en la Declaración de Paz, pues "la MOMEP permitió la consolidación del proceso de paz y su presencia en la zona de conflicto obligó a respetar el cese de fuego" (FERNÁNDEZ, 1999, p. 251). A pesar de su limitada función de separación y extracción de las fuerzas, su presencia permitió un efectivo desarrollo del proceso de negociación. Consiguió mantener la paz a pesar de la existencia de sensibilidades entre ambos Estados lo cual hacía muy probable el rompimiento del cese de fuego.

El 18 de enero del año 1996 los cancilleres de Perú y Ecuador se reúnen en Buenos Aires y deciden resolver los puntos de los impases recurriendo al Protocolo de 
Rio de Janeiro. Esto sin duda causa conmoción a Ecuador por ser un golpe contrario al cual se impartió en la Declaración de Paz del Itamaraty, puesto que en la misma se pretendía apartar al Protocolo como referencia de solución. En octubre del mismo año se firmará el Acuerdo de Santiago que posteriormente será aplicado de manera estratégica para la resolución de los impases. Ya para el año de 1997, en sus primeros meses, se reúnen las delegaciones de los dos países produciendo así la "Declaración de Brasilia" mediante la cual se crean comisiones con el fin de analizar y dar solución a los impases.

El 10 de agosto de 1998 Ecuador inicia un nuevo gobierno bajo la presidencia de Jamil Mahuad. Este a su vez recurre rápidamente a la negociación directa con el presidente Fujimori. De este acercamiento emerge una carta dirigida al Presidente Fernando Henrique Cardoso el día 8 de octubre de 1998 en la cual los presidentes Mahuad y Fujimori invocan el artículo IV del Acuerdo de Santiago de 1996 donde se recalca lo siguiente,

Los Países Garantes conforme con la responsabilidad que les impone su función de ayuda a la Partes, propondrán los procedimientos más adecuados para la solución definitiva de los puntos de desacuerdo que las partes no hayan logrado dirimir en forma directa. (ACUERDO DE SANTIAGO, 1996)

De este modo ambos Estados se comprometen a cumplir con el pronunciamiento y juicio que emitan los países garantes. Quince días posteriores a dicha carta, los países garantes emiten un Dictamen en el cual anexan los puntos por donde deben ser colocados los hitos para la delimitación de la zona inconclusa. De la misma manera, informan que Perú dará como propiedad privada al Gobierno de Ecuador un área de un kilómetro cuadrado, punto conocido como Tiwintza. Siendo así, el día 26 de octubre de 1998 los presidentes de Ecuador y Perú, juntamente con los jefes de Estado de los Países Garantes, rubricaron el acta de Brasilia mediante la cual aceptaban que por el dictamen de los Países Garantes quedan resueltos los problemas entre Ecuador y Perú. Es así que se da fin a los problemas limítrofes entre ambos Estados. 


\section{CONCLUSIONES}

Es importante resaltar tres puntos esenciales emitidos a partir del presente trabajo dentro de lo que es el proceso de trasformación del conflicto del Cenepa hacia una paz duradera. La primera hace referencia a la caracterización del conflicto para tener un mejor entendimiento del mismo. La segunda se refiere al proceso de negociación o mediación dentro del proceso de paz. Finalmente, se toma como punto de referencia el instrumento de la Misión de Observadores Militares Ecuador-Perú para el análisis. En primer lugar, el conflicto del Cenepa puede ser caracterizado como un "conflicto armado de intensidad menor" puesto que presenta características que lo encuadran en este marco. Además, según lo distinguido por Mary Kaldor, este conflicto también presenta características encontradas en las "viejas guerras" debido a su choque específicamente de carácter militar.

Un segundo punto referente al proceso de negociación entiende que el conflicto tuvo momentos en los cuales predominó la negociación. Pues, mediante representantes del Ejecutivo, como cancilleres o incluso los mismos primeros ministros, que fueron partícipes de diálogos con el fin de resolver las diferencias existentes. Por otro lado, la fase final de la negociación concluye con invocar la pertinencia de la mediación de los Países Garantes. Son los representantes de estos países quienes mediante el Dictamen del 23 de octubre de 1998 plantean la solución al litigio entre Ecuador y Perú, siendo aceptada esta resolución vinculante. Siendo así, se concluye que ambos instrumentos, negociación y mediación, fueron vitales para la resolución del conflicto.

Finalmente, la Misión de Observadores Militares Ecuador-Perú (MOMEP) tuvo una gran relevancia dentro de la resolución del conflicto. Su presencia puede ser entendida como parte de la mediación de los Países Garantes. Sin duda su acción de impulsar un cese de fuego, una separación de fuerzas y crear una zona desmilitarizada fue vital para que la vía diplomática pueda concluir sus labores sin preocupación de que los encuentros bélicos escalen hasta una guerra. Esto demuestra que el peacekeeping tradicional de las Naciones Unidas, a pesar de sus limitantes a la observación y cese de fuego, permite una efectiva solución. Por último, cabe destacar que la MOMEP al no ser impulsada por las Naciones Unidas, permite una base fundamentada de cómo emprender una misión de observación y de paz en casos regionales de conflictos. 


\section{REFERENCIAS}

ACUERDO DE SANTIAGO. Santiago, 1996.

BARRETO, Andrés. Viejas y nuevas guerras: realidades jurídicas de los conflictos armados contemporáneos. 2011. Disponible en: <http://www.unilibre.edu.co/verbaiuris/25/viejas-y-nuevas-guerras-realidadesjuridicas-de-los-conflictos-armados-contemporaneos.pdf $>$ Accesado en: 08 de abril de 2015.

BATISTA, Nilton José. A participacao do Brasil no processo de paz Equador-Peru. In: CRUZ, Luiz (Coord.). Brasil em Missoes de Paz. Sao Paulo: Usina do Livro, 2005.

BURNE0, María Fernanda. Prensa y Nacionalismo: Representaciones en la Guerra del Cenepa en Febrero de 1995. 2010. Disponible en: <http://www.flacsoandes.edu.ec/comunicacion/aaa/imagenes/publicaciones/pub_212. pdf> Accesado en: 12 de abril de 2015.

BUZAN, Barry; HANSEN, Lene. La evolución de los Estudios de Seguridad Internacional.

Sao Paulo: Ed. Unesp, 2012.

CARTA DE LAS NACIONES UNIDAS. San Francisco, 1945. Disponible en: <http://www.un.org/es/documents/charter/> Accesaro en: 12 de abril de 2015.

CONSTITUCIÓN DEL ECUADOR, 1830. Disponible en: <http://jazmindelandin.blogspot.com.br/2014/07/constitucion-del-ecuador-18301843.html>. Accesado en: 12 de abril de 2015.

CRUZ, Sergio. Brasil em Missoes de Paz. Sao Paulo: Usina do Livro, 2005.

DOMÍNGUEZ, Jorge. Los Conflictos Internacionales en América Latina y la Amenaza de Guerra. $1984 . \quad$ Disponible en: <http://codex.colmex.mx:8991/exlibris/aleph/a18_1/apache_media/T7M7SDL42AEYT H82QUB84MHDRLUDC8.pdf> Accesado en: 12 de abril de 2015.

EJÉRCITO ECUATORIANO. Victoria en el Cenepa. Quito, 2011.

ESPINOSA, Carlos. La negociación como terapia: memoria, identidad y honor Nacional en el proceso de paz Ecuador-Perú. In: BONILLA, Adrián (Coord.) Ecuador-Perú. Horizontes de la negociación y el conflicto. Quito: Rispergraf, 1999. Disponible en: <http://www.flacsoandes.edu.ec/libros/digital/50982.pdf> Accesado en: 12 de abril de 2015.

FERNÁNDEZ, Marcelo. De la Declaración del Itamaraty al Acta Presidencial de Brasilia. In: EJÉRCITO ECUATORIANO. Victoria en el Cenepa. Quito, 2011. 
GALTUNG, Johan. Violence, Peace, and Peace Research. Oslo, 1969. Disponible en: <http://jpr.sagepub.com/content/6/3/167.citation> Accesado en: 12 de abril de 2015. en:<

GALTUNG, Johan. Twenty-Five Years of Peace Research. Berlin, 1985. Disponible https://www.transcend.org/galtung/papers/Twenty\%20Five\%20Years\%20of\%20Peac e\%20Research-Ten\%20Challenges\%20and\%20Some\%20Responses.pdf> Accesado en: 12 de abril de 2015.

GRAY, Colin. The 21st Century Security Environment and the Future of War. 2009. Disponible en: <http://strategicstudiesinstitute.army.mil/pubs/parameters/Articles/08winter/gray.p df > Accesado en: 12 de abril de 2015.

JUDT, Tony. Pós-guerra: Uma história da Europa desde 1945. Río de Janeiro: Objetiva, 2008.

KALDOR, Mary. Un nuevo enfoque sobre las guerras. 2006. Disponible en: <http://www.fcp.uncu.edu.ar/upload/nuevoenfoqueguerrasmarykaldor.pdf> Accesado en: 12 de abril de 2015.

MONCAYO, Paco. Poder y Conflicto. Quito: El Conejo, 2014.

MONCAYO, Paco. Los agrupamientos tácticos. In: EJÉRCITO ECUATORIANO. Victoria en el Cenepa. Quito, 2011.

NACIONES UNIDAS. United Nations Peacekeeping Operations, principles and guidlines. New York, 2008. Disponible en: <http://www.un.org/en/peacekeeping/operations/principles.shtml> Accesado en: 12 de abril de 2015 .

NEWMAN; RICHMOND; PARIS. New perspectives on liberal peacebuilding. United Nations Univesity Press. 2010.

PROTOCOLO DE PAZ, AMISTAD Y LÍMITES ENTRE EL ECUADOR Y PERÚ. Rio de Janeiro, 1942.

REMIRO, Antonio. Derecho Internacional. Valencia: Tirant Lo Blanch, 2007.

ROUSSEAU, Jean Jacobs. El contrato social. 1999. Disponible en: <http://www.enxarxa.com/biblioteca/ROUSSEAU\%20El\%20Contrato\%20Social.pdf> Accesado en: 07 de abril de 2015.

SEITENFUS, Ricardo. [Os novos paradigmas da seguranca coletiva internacional. In: CRUZ, Luiz (Coord.). Brasil em Missoes de Paz. Sao Paulo: Usina do Livro, 2005.

TELLO, Jorge. Un conflicto inminente. In: EJÉRCITO ECUATORIANO. Victoria en el Cenepa. Quito, 2011. 
UPPSALA CONFLICT DATA PROGRAM. Department of Peace and Conflict Research. 1970. Disponible en: <http://www.pcr.uu.se/research/ucdp/definitions/> Accesado en: 12 de abril de 2015. 